\title{
Pemodelan Deteksi Krisis Keuangan di Indonesia Berdasarkan Indikator M2/Cadangan Devisa
}

\author{
Aisyah Zahrotul Hidayah ${ }^{1, *}$, Sugiyanto ${ }^{1}$, Isnandar Slamet ${ }^{2}$ \\ 1, 2 Program Studi Statistika; Universitas Sebelas Maret; \\ E-mail: ${ }^{1}$ aishida@ student.uns.ac.id, ${ }^{1}$ sugiyanto61@ @ staff.uns.ac.id, ${ }^{2}$ isnandarslamet@ staff.uns.ac.id \\ Program Studi Statistika; Universitas Sebelas Maret; \\ * Korespondensi: e-mail: aishida@student.uns.ac.id
}

\section{ARTICLE INFO}

\section{ABSTRACT}

\begin{abstract}
The banking crisis reflects the liquidity crisis and bankruptcy of banks in the financial system. The financial crisis that occurred in mid-1997 resulted in a financial crisis that had a severe impact on the Indonesian economy. This made it aware of the importance of building a financial crisis early detection system to prepare for a crisis. The crisis occurs due to several macroeconomic indicators undergoing structural changes (regimes) and contain very high fluctuations. Combined volatility models and Markov regime switching are very suitable for explaining crises. The M2/international reserves indicator from 1990 to 2018 was used to build a crisis model. The results showed that the Markov regime switching autoregressive conditional heteroscedasticity model MRS-ARCH(2,1) could explain the crisis that occurred in mid-1997. Based on this model, in the future the crisis might occur if the M2/international reserves indicator decreased minimum of $13 \%$
\end{abstract}

\section{PENDAHULUAN}

Krisis perbankan mencerminkan krisis likuiditas dan kebangkrutan bank dalam sistem keuangan. Krisis perbankan merupakan salah satu penyebab terjadinya krisis keuangan (Kawai et al., 2001). Dalam dua dekade terakhir, Indonesia dilanda dua krisis keuangan besar (krisis tahun 1997 yang dimulai pada bulan Juli disebut krisis Asia dan krisis tahun 2008 yang dimulai pada bulan Oktober disebut krisis global) dan beberapa krisis keuangan kecil (salah satunya krisis yang terjadi pada tahun 2005 yang dimulai pada bulan Oktober). Krisis keuangan yang terjadi pertengahan tahun 1997 yang dimulai ketika nilai mata uang Thailand turun tajam. Dampak krisis 1997 masih terasa hingga saat ini karena negara memiliki beban akibat hutang luar negeri pada masa krisis berlangsung. Dampak krisis keuangan yang sangat parah pada perekonomian Indonesia menyadarkan akan pentingnya membangun sistem deteksi dini guna mengantisipasi terjadinya krisis di masa yang akan datang. Beberapa indikator yang menunjukkan perilaku tidak biasa (fluktuasi yang sangat tinggi dan adanya perubahan kondisi) ketika krisis terjadi dapat digunakan sebagai sistem pendeteksian dini untuk krisis keuangan (Kaminsky et al., 1997). Indikator M2/cadangan devisa merupakan salah satu indikator krisis yang mungkin dapat menggambarkan kondisi perbankan di Indonesia sehingga dapat dikatakan sebagai indikator kondisi perbankan. Penurunan yang sangat tajam pada indikator M2/cadangan devisa dapat menyebabkan krisis.

Indikator kondisi perbankan diindikasikan memiliki efek heteroskedastisitas sehingga model volatilitas sangat baik untuk menjelaskannya. Beberapa model volatilitas yang pernah dikenalkan oleh para ahli yaitu autoregressive conditional heteroscedasticity (ARCH) (Engle, 1982), generalized autoregressive conditional heteroscedasticity (GARCH) (Bollerslev, 1986), dan exponential generalized autoregressive conditional heteroscedasticity (EGARCH) (Nelson, 1991). Perubahan kondisi (regime) yang terabaikan pada model volatilitas merupakan variabel tak teramati (Hamilton, 1989) akan dijelaskan oleh Markov regime switching.

Gabungan model Markov regime switching dan ARCH (SWARCH) yang diaplikasikan pada data US gross national product (GNP) tahun 1952 sampai 1984 dapat menjelaskan perubahan kondisi dan menggambarkan volatilitas data dengan baik (Hamilton \& Susmel, 1994). Identifikasi volatilitas pasar saham dan nilai tukar di Korea dan krisis keuangan global merupakan salah satu penerapan model SWARCH 
(Chang et al., 2010). Penelitian lain tentang krisis keuangan melalui gabungan model volatilitas dan Markov regime switching melalui model MS-ARCH $(3,1)$ dapat mengidentifikasi krisis keuangan pada tahun 1997 dan 2008 berdasarkan indikator output riil, kredit domestik per PDB, dan IHSG (Sugiyanto et al., 2018b). Selain itu, penelitian menggunakan indikator perbankan dapat mendeteksi krisis yang sebenarnya (Sugiyanto et al., 2018a). Penelitian ini mencari model terbaik yang selanjutnya dapat digunakan sebagai deteksi krisis keuangan pada masa yang akan datang.

\section{METODE PENELITIAN}

Penelitian ini merupakan studi kasus pada salah satu indikator krisis Kaminsky yaitu M2/cadangan devisa. Data bulanan M2/cadangan devisa periode 1990 sampai 2018 diperoleh dari International Financial Statistics (IFS). Langkah awal dalam penelitian ini yaitu melihat kestasioneran data melalui pola data dan uji augmented Dickey Fuller (ADF). Apabila data tidak stasioner maka dilakukan transformasi data menggunakan log return.

Salah satu model yang sering digunakan untuk pemodelan data runtun waktu yaitu model autoregressive moving average (ARMA), yang dapat dituliskan sebagai berikut (Tsay, 2010)

$r_{t}=\sum_{i=1}^{p} \phi_{i} r_{t-i}-\sum_{j=1}^{q} \theta_{j} a_{t-j}+a_{t}$

dimana $r_{t}$ merupakan log return pada waktu $t, a_{t}$ adalah residu model ARMA, $\phi_{i}$ adalah parameter model AR, dan $\theta_{j}$ adalah parameter model MA. Pada model terbaik ARMA dilakukan uji heteroskedastisitas residu untuk melihat kekonstanan variansi residu model. Apabila variansi residu model ARMA tidak konstan maka dilakukan clustering atau pengelompokan pada residu model ARMA menggunakan jarak dynamic time warping (DTW). Model volatilitas autoregressive conditional heteroscedasticity (ARCH) merupakan salah satu alternatif untuk memodelkan variansi yang tidak konstan dapat dituliskan sebagai berikut (Engle, 1982) $\sigma_{t}^{2}=\alpha_{0}+\sum_{i=0}^{m} \alpha_{i} a_{t-i}^{2}$

dimana $\alpha_{t} \stackrel{i=0}{=} \sigma_{t} \epsilon_{t}$ merupakan residu model ARMA pada waktu $t$ dan $\sigma_{t}^{2}$ adalah variansi bersyarat dari residu pada waktu $t$. Uji diagnostik yang meliputi uji heteroskedastisitas (pengali Lagrange), uji normalitas (Kolmogorov-Smirnov), dan uji autokorelasi (Ljung-Box) dilakukan untuk mengetahui apakah model runtun waktu yang diperoleh baik untuk digunakan.

Model volatilitas dapat menjelaskan variansi tidak konstan tetapi tidak dapat menjelaskan perubahan kondisi. Perubahan kondisi pada data runtun waktu dapat dijelaskan dengan model Markov regime switching (Hamilton, 1989). Dalam Markov regime switching perubahan kondisi yang terjadi pada model tidak dianggap sebagai suatu hasil peristiwa yang diketahui secara pasti (deterministik) tetapi sebagai suatu hasil variabel random tak teramati atau disebut dengan regime. Gabungan model volatilitas dan model Markov regime switching dapat menjelaskan variansi tidak konstan dan perubahan kondisi. Model Markov regime switching autoregressive conditional heteroscedasticity (MRS-ARCH) dapat dituliskan sebagai berikut (Hamilton \& Susmel, 1994)

$r_{t}=\mu_{s_{t}}+a_{t}$,

$a_{t}=\sigma_{t} \epsilon_{t}$

$\sigma_{t, s_{t}}^{2}=\alpha_{0, s_{t}}+\sum_{i=1}^{m} \alpha_{i, s_{t}} a_{t-i}^{2}$

dimana $r_{t}$ merupakan nilai log retrun dan $s_{t}$ menunjukkan variabel random yang tidak teramati memenuhi orde pertama rantai Markov yang dapat mengambil nilai $1,2, \ldots$ T dengan asumsi mengikuti proses Markov orde pertama dengan probabilitas transisi $p_{i j}$. Parameter distribusi bersyarat dan variabel acak yang tidak teramati dengan probabilitas transisis konstan diberikan oleh

$$
P\left[s_{t}=j \mid s_{t-1}=i\right]=p_{i j}, \sum_{j=1}^{T^{T}} p_{i j}=1, \text { untuk } i, j=1,2, \ldots, T .
$$

dimana menunjukkan elemen-elemen dari matriks transisisi bahwa regime $i$ akan diikuti oleh regime $j$, untuk kondisi dua state $i, j \in$. Sinyal krisis jangka pendek dapat ditunjukkan dari jumlah nilai prediksi probabilitas smoothed. Dalam notasi matriks, P dapat didefinisikan oleh 


$$
\mathbf{P}=\left(\begin{array}{cccc}
p_{11} & p_{21} & \ldots & p_{T} \\
p_{12} & p_{22} & \ldots & p_{7} \\
\vdots & \vdots & \ddots & \vdots \\
p_{1 T} & p_{2 T} & \ldots & p_{T}
\end{array}\right.
$$

Smoothed probability merupakan probabilitas suatu regime pada waktu $t$ berdasarkan informasi dari seluruh data pengamatan, dapat dituliskan sebagai berikut (Kim \& Nelson, 2017)

$\operatorname{Pr}\left(S_{t}=i \mid \psi_{T}\right)=\sum_{s=1}^{T^{T}} \operatorname{Pr}\left(S_{t+1}=s \mid \psi_{T}\right) \operatorname{Pr}\left(S_{t}=i \mid S_{t+1}=T, \psi_{T}\right)$,

dimana $\psi_{t}$ merupakan semua himpunan informasi sampai waktu $t$.

\section{HASIL DAN PEMBAHASAN}

Pola data M2/cadangan devisa dapat diidentifikasi menggunakan plot data runtun waktu. Plot data M2/cadangan devisa dapat dilihat pada Gambar 1.

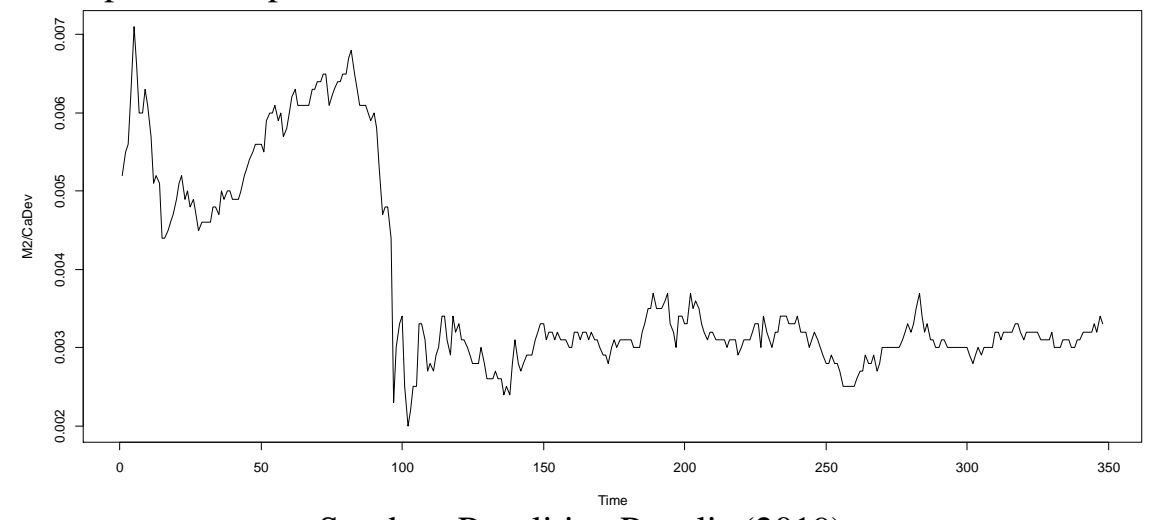

Sumber: Penelitian Penulis (2019)

Gambar 1. Plot indikator M2/cadangan devisa

Gambar 1 menunjukkan bahwa plot data M2/cadangan devisa mengindikasikan data tidak stasioner baik terhadap mean maupun variansi karena terjadi fluktuasi dari waktu ke waktu. Selain itu, uji kestasioneran data dapat dilihat menggunakan uji augmented Dickey Fuller (ADF). Berdasarkan uji ADF, diperoleh nilai probabilitas lebih dari 0,05 yang berarti bahwa data tidak stasioner. Selanjutnya dilakukan transformasi log return yang dapat dilihat pada Gambar 2.

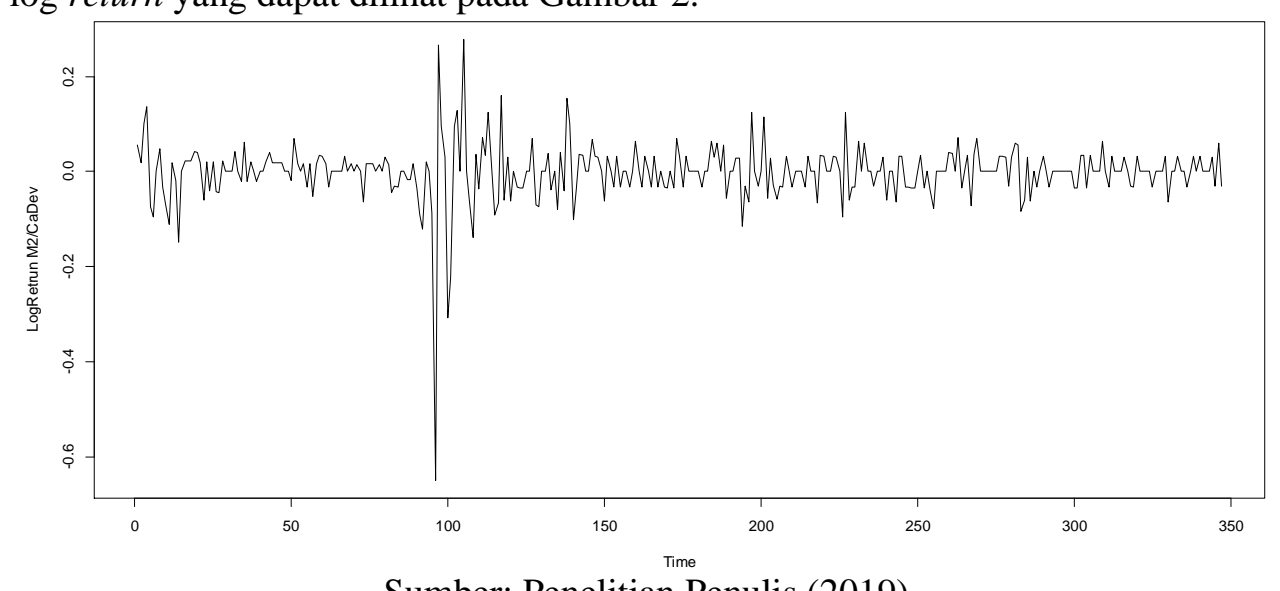

Sumber: Penelitian Penulis (2019)

Gambar 2. Plot transformasi log return indikator M2/cadangan devisa

Gambar 2 menunjukkan bahwa plot data M2/cadangan devisa megindikasikan data sudah stasioner. Uji augmented Dickey Fuller (ADF) dapat juga digunakan untuk melihat kestasasioneran data. Berdasarkan uji ADF, diperoleh nilai probabilitas kurang dari 0,05 yang berarti bahwa data sudah stasioner. Setelah diperoleh data stasioner maka dicari model ARMA. Berdasarkan nilai AIC, diperoleh model ARMA terbaik yaitu ARMA $(1,1)$ yang dituliskan sebagai berikut

$r_{t}=0,520 r_{t-1}+0,6401 a_{t-1}$ 
dimana $r_{t}$ merupakan log return pada waktu $t$ dan $a_{t}$ adalah residu model ARMA. Berdasarkan uji pengali Lagrange, diperoleh nilai probabilitas lebih kecil dari 0.05. Hal ini berarti bahwa residu model ARMA mengandung heteroskedastisitas atau variansi tidak konstan. Apabila variansi residu model ARMA tidak konstan maka dilakukan pengelompokan volatilitas. Hal ini diperkuat dengan Gambar 3a yang menunjukkan bahwa residu model ARMA berbentuk leptokurtik. Kurva leptokurtik mengindikasikan adanya nilai range yang berbeda, sehingga perlu dilakukan clustering. Analisis clustering yang tepat untuk data time series yaitu analisis cluster menggunakan jarak DTW (Dynamic Time Warping). Berdasarkan hasil clustering, diperoleh jumlah cluster yang sesuai untuk M2/cadangan devisa yaitu 2, dengan cluster 1 memuat volatilitas rendah dan cluster 2 memuat volatilitas tinggi.

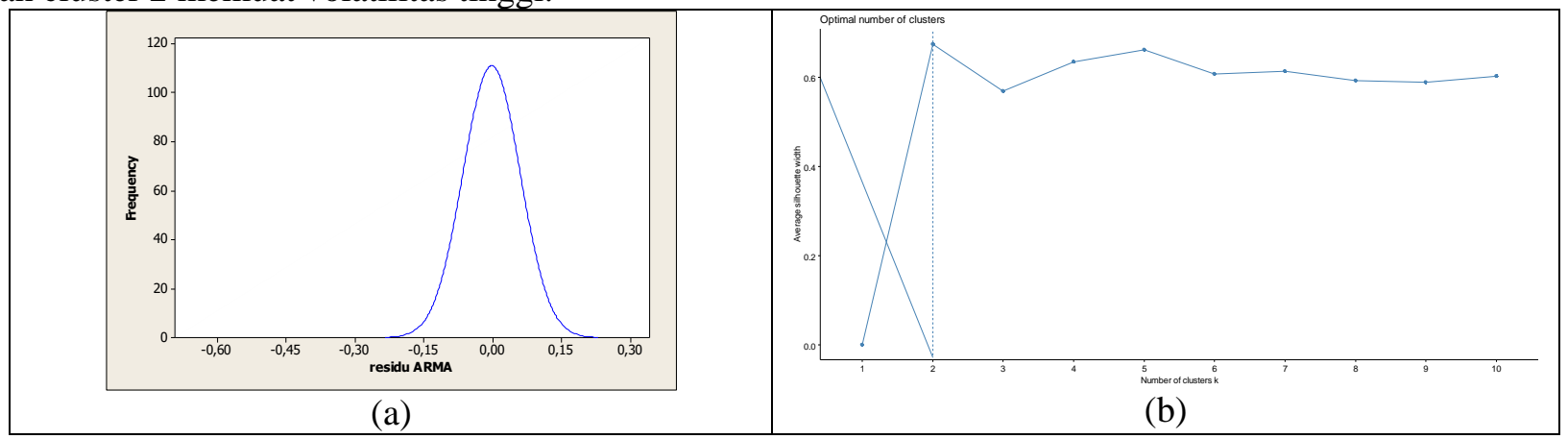

Sumber: Penelitian Penulis (2019)

Gambar 3. (a) Keruncingan kruva dari residu ARMA dan (b) jumlah cluster yang optimal

Selanjutnya, untuk mengatasi variansi tidak konstan digunakan model volatilitas. Model volatilitas ARCH(1) dapat ditulis sebagai berikut

$\sigma_{t}^{2}=1,686 e-03+0,9303 a_{t-1}^{2}$

dimana $a_{t}$ adalah residu model ARMA. Berdasarkan uji diagnostik diperoleh nilai probabilitas lebih dari 0,05 yang berarti bahwa asumsi model runtun waktu terpenuhi (residu model volatilitas sudah homogen, berdistribusi normal, dan tidak mengandung autokorelasi).

Regime merupakan perubahan kondisi yang terjadi dalam model Markov regime switching. Regime diasumsikan mengikuti orde pertama rantai Markov dengan probabilitas transisi $p_{i j}$ dengan $i, j=1,2$. Sehingga, model Markov switching generalized autoregressive heteroscedasticity MRS-ARCH $(2,1)$ merupakan model $\mathrm{ARCH}(1)$ yang memiliki 2 regime, dengan regime 1 menggambarkan volatilitas rendah dan regime 2 menggambarkan volatilitas tinggi. Suatu regime mempunyai kemungkinan untuk bertahan pada regime yang sama atau pindah ke regime yang lain pada waktu berikutnya. Probabilitas dari perubahan regime dapat dilihat dalam bentuk matriks probabilitas transisi. Hasil perhitungan matriks probabilitas transisi sebagai berikut

$$
P=\left(\begin{array}{ll}
0.9845 & 0.0155 \\
0.0754 & 0.9246
\end{array}\right)
$$

Berdasarkan matriks probabilitas transisi tersebut, dapat dilihat nilai probabilitas untuk bertahan pada volatilitas rendah sebesar 0.9845 dan probabilitas untuk bertahan pada volatilitas tinggi sebesar 0.9246 .

Untuk mendeteksi krisis, dapat dilihat dari nilai probabilitas smoothed paling rendah pada saat krisis terjadi di Indonesia (1997-1998). Sehingga diperoleh hasil krisis terjadi ketika nilai probabilitas smoothed lebih dari 0.9. Plot nilai probabilitas smoothed dapat dilihat pada Gambar 4.

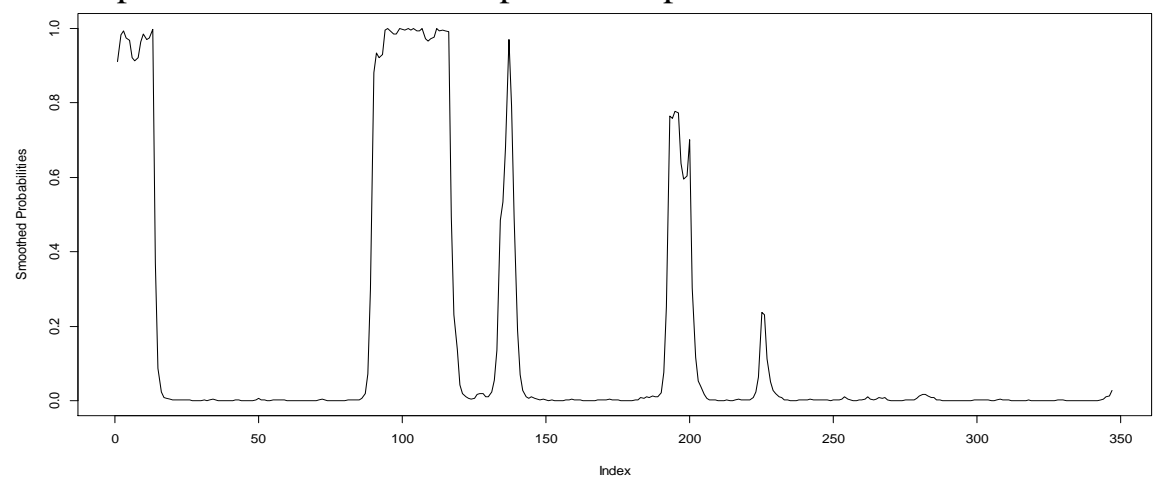

Sumber: Penelitian Penulis (2019) 
Gambar 4. Probabilitas smoothed indikator M2/cadangan devisa

Terdapat 39 nilai probabilitas smoothed yang lebih besar dari 0.9 pada Gambar 4 yang mendeteksi krisis pada Maret 1990 - Februari 1991, Agustus 1997 - September 1999, Juni 2001. Sehingga, dapat disimpulkan bahwa model MRS-ARCH(2,1) dapat mendeteksi krisis untuk indiaktor M2/cadangan devisa. Berdasarkan nilai probabilitas smoothed, indikator M2/cadangan devisa dapat menunjukkan sinyal yang cepat dalam mendeteksi krisis. Hal ini dikarenakan krisis yang sebenarnya terjadi mulai Juli 1997, sedangkan indikator M2/cadangan devisa memberikan sinyal krisis mulai Agustus 1997. Akan tetapi indikator M2/cadangan devisa tidak bisa menangkap krisis yang terjadi pada tahun 2005 dan 2008.

Selanjutnya dilakukan simulasi pada nilai probabilitas smoothed yang akan datang dan diperoleh hasil seperti pada Gambar 5.

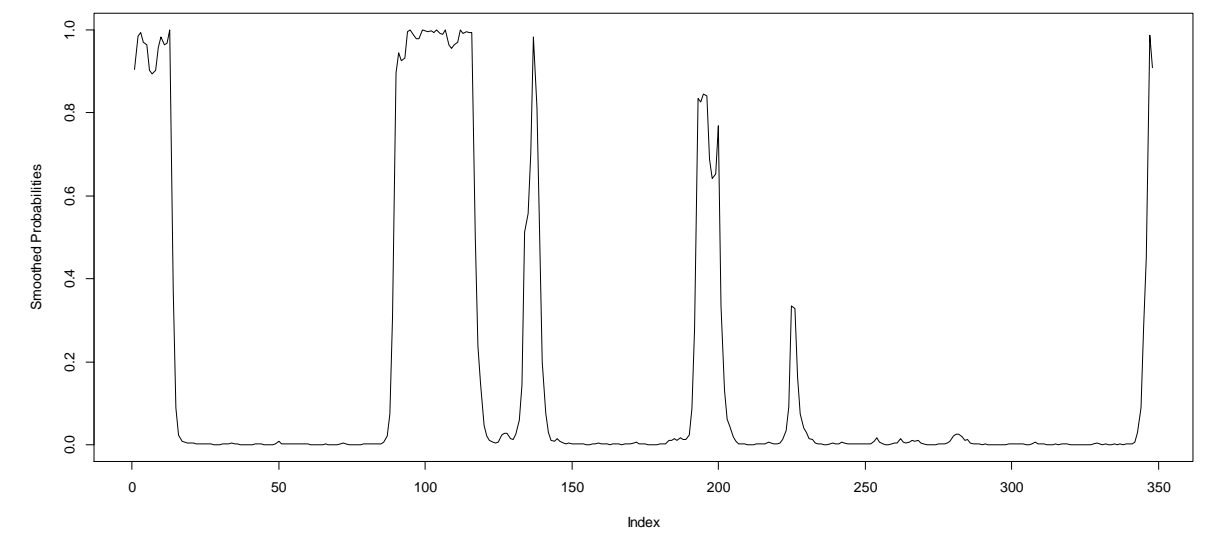

Sumber: Penelitian Penulis (2019)

Gambar 5. Probabilitas smoothed dari simulasi indikator M2/cadangan devisa

Bila M2/cadangan devisa mengalami penurunan pada data terakhir sebesar 13\% maka akan terjadi krisis. Hal ini dapat dilihat pada Gambar 5 yang menunjukkan bahwa pada akhir periode terjadi krisis.

\section{KESIMPULAN}

Model yang tepat untuk indikator rasio suku bunga pinjaman dan simpanan adalah MRS-ARCH(2, 1). Berdasarkan model tersebut didapatkan hasil bila pada periode Januari 2019 indikator M2/cadangan devisa mengalami penurunan $13 \%$ maka dapat terjadi krisis.

\section{REFERENSI}

Bollerslev, T. 1986. Generalized Autoregressive Conditional Heteroscedacity. Journal of Econometrics, 31(3): 307-327.

Chang, K., Cho, K.Y. \& Hong, M.-G. 2010. Stock Volatility, Foreign Exchange Rate Volatility and the Global Financial Crisis. Journal of Economic Research, 15: 249-272.

Engle, R.F. 1982. Autoregressive Conditional Heteroscedasticity with Estimates of the Variance of United Kingdom Inflation. Econometrica, 50(4): 987.

Hamilton, J.D. 1989. A New Approach to the Economic Analysis of Nonstationary Time Series and the Business Cycle. Econometrica, 57(2): 357.

Hamilton, J.D. \& Susmel, R. 1994. Autoregressive conditional heteroskedasticity and changes in regime. Journal of Econometrics, 64(1-2): 307-333.

Kaminsky, G., Lizondo, S. \& Reinhart, C. 1997. Leading Indicators of Currency Crises. International Monetary Fund Working Paper No. 97/79.

Kawai, M., Newfarmer, R. \& Schmukler, S. 2001. Crisis and Contagion in East Asia: Nine Lessons. The World Bank, Policy Research Working Paper Series: 2610. Washington DC.

Kim, C.J. \& Nelson, C.R. 2017. State-Space Models with Regime Switching. The MIT Press.

Nelson, D.B. 1991. Conditional Heteroskedasticity in Asset Returns: A New Approach. Econometrica, 59(2): 347.

Sugiyanto, Zukhronah, E. \& Sari, S.P. 2018a. Detection method of financial crisis in Indonesia using MSGARCH models based on banking condition indicators. Journal of Physics: Conference Series, 1025: 012118. 
Sugiyanto, Zukhronah, E. \& Setianingrum, M. 2018b. The detection of financial crisis using combination of volatility and markov switching models based on real output, domestic credit per GDP, and ICI indicators. Journal of Physics: Conference Series, 1025: 012115.

Tsay, R.S. 2010. Analysis of Financial Time Series. Wiley Series in Probability and Statistics. USA: John Wiley \& Sons, Inc. 